\title{
The delivery of ophthalmic care: the practitioner, community ophthalmic teams, and contract ophthalmology
}

It is generally accepted that the delivery of ophthalmic care, both nationally and internationally, is limited by lack of resources. However, present resources could be used more effectively for the treatment and prevention of eye disease by the better coordination of existing services.

On a national level, the coordination of the work of "eye care professionals" would focus ophthalmic activity without threatening the standing of individual practitioners. On an international level, the coordination of agencies involved in the delivery of eye care-governments, international bodies, charities, medical personnel, carerswould create the opportunities for total ophthalmic care to communities. Many isolated examples of such coordination already exist.

How might this work?

\section{On a national level}

In the United Kingdom, total ophthalmic care in a community, involving treatment and prevention, is an ideal that cannot be achieved by the existing complement of ophthalmologists. However, ophthalmology comprising nearly 800 consultants, about 1400 subconsultant grades and trainees, and others more peripherally involved (nurse practitioners, general practitioners, school medical officers, charitable workers), also includes more than 8000 optometrists and 1100 orthoptists.

Society expects the ophthalmic services to provide treatment (for eye diseases, refractive problems, and functional disorders), prevention (mainly involved with screening), and advice (public health ophthalmology). The personnel required to perform these services largely exist but do not act efficiently as teams. A community ophthalmic team, consisting of ophthalmologists, optometrists, and orthoptists with associated personnel, such as nurse practitioners, interested physicians, and community workers, could coordinate ophthalmic care more effectively.

Some changes in outlook would be required.

Ophthalmologists would need to acquire a greater awareness of community needs and (for a few) training in the leadership of a team of "eye care professionals," a community ophthalmic team. Consultant ophthalmologists, by virtue of their training, their responsibilities, and their experience, would make the most appropriate leaders of such teams.

Optometrists, by far the largest group, have much to contribute, primarily in the management of refractive disorders. However, their place in preventive ophthalmology is growing and the usefulness and quality of their work would certainly further increase if they were part of a community ophthalmic team. This would, with a realistic adjustment of their training, help to fulfil their medical ambitions.

Orthoptists, specialising in ocular motility disorders, naturally spend a lot of their time with children. With some adjustment to their training they could become specialists in child screening (for which they are already recognised), in child refraction (taught in their degree course), and in some areas of ophthalmic technology.
Associated personnel. The place of nurse practitioners in ophthalmic delivery is already being greatly enhanced. Others, including charities, would be associated with such teams.

Thus, the establishment of community ophthalmic teams, consisting of current ophthalmic personnel, offers an opportunity for enhanced community care, increased professional satisfaction, greater academic accountability, and more focused ophthalmic activity. It is a way of achieving an ideal within the framework of existing resources.

This concept could be tested in a pilot study within a defined community.

\section{On an international level}

Ophthalmic care is very unevenly distributed in the world and yet ophthalmology is one of the more effective medical specialties in terms of improving the quality of life. There are many groups, including international bodies, governmental agencies, and charities, involved in the prevention and alleviation of blindness. However, the delivery of ophthalmic care in the world generally can often appear haphazard even though the total funding from all sources is significant.

In association with the International Agency for the Prevention of Blindness, the World Health Organization is involved through its prevention of blindness programme and aims to coordinate much of the work being undertaken in this area within the Vision 2020 campaign. This will place emphasis on the training of "mid-level personnel." On a national level, a proposed "forum" of blind charities hopes to achieve more cohesion to their work.

By coordinating the ophthalmic services for a community it should be possible to provide less haphazard careperhaps by a system of contract ophthalmology. By contract ophthalmology is meant total ophthalmic care of a community of whatever size, including optical services, screening, medical and surgical ophthalmic treatment, and education. In providing contract ophthalmology existing local resources, both human and material, would be better used and more accessible. Relevant external funding would be provided, depending on local needs and facilities, to the advantage of specific communities and their individual ophthalmic practitioners.

Contract ophthalmology would be the channel through which public bodies and private charities and individuals could use their funds in a highly visible and audited manner. They would be distributed according to the needs of a particular community. Even affluent communities, including National Health Service trusts, might wish to purchase such a facility.

The expertise required to set up a contract ophthalmology service for a community would be available from a variety of organisations such as suitable international agencies, certain academic departments, and major charities (such as Sight Savers). Defining the functions of the different ophthalmic groups and auditing their activities would be part of this expertise. 
A pilot study might initially be provided by an academic department or an international agency.

\section{Conclusion}

By the twin concepts of community ophthalmic teams and contract ophthalmology, ophthalmic care on national and international levels can be enhanced for the benefit of both the communities served and the carers themselves-largely within existing resources.

ROLF BLACH

Henley on Thames, UK

If you wish to comment on any article published in the British Journal of Ophthalmology you can send an eLetter using the eLetters link at the beginning of each article. Your response will be posted on British Journal of Ophthalmology online within a few days of receipt (subject to editorial screening).

www.bjophthalmol.com 